\title{
A Novel Asymmetrical Single-Phase Multilevel Inverter Suitable for Hybrid Renewable Energy Sources
}

\author{
C. P. Boopathy ${ }^{1}$, M. Kaliamoorthy ${ }^{2}$ \\ ${ }^{1}$ Department of Electrical and Electronics Engineering, SVS College of Engineering, Coimbatore, India \\ ${ }^{2}$ Department of Electrical and Electronics Engineering, Karpagam College of Engineering, Coimbatore, India \\ Email: cpbsvs@gmail.com, kaliasgoldmedal@gmail.com
}

Received 15 April 2016; accepted 16 May 2016; published 20 May 2016

Copyright (C) 2016 by authors and Scientific Research Publishing Inc.

This work is licensed under the Creative Commons Attribution International License (CC BY).

http://creativecommons.org/licenses/by/4.0/

cc) (i)

\section{Abstract}

This paper introduces a novel single-phase asymmetrical multilevel inverter suitable for hybrid renewable energy sources. The proposed inverter consists of two isolated DC sources and six power semiconductor controlled switches. The suggested inverter is capable of generating sevenlevel output when the input DC voltage is taken in the ratio of 1:2. The higher magnitude DC source is fed from Photo Voltaic (PV) panels, whereas the lower magnitude DC source is fed from Wind Turbine (WT) driven Permanent Magnet DC (PMDC) generator. Both the renewable energy sources are connected to the inverter via two DC-DC boost converters connected in cascade (i.e. one for maximum power point tracking and another for DC-link voltage control). The proposed hybrid renewable energy source inverter is connected to single-phase grid via proper control systems. The complete system is simulated using MATLAB/SIMULINK and the results are presented in detail.

\section{Keywords}

Asymmetrical Multilevel Inverter, DC-DC Boost Converter, Photo-Voltaic, Wind Turbine, Permanent Magnet DC Generator, Maximum Power Point Tracking

\section{Introduction}

In recent years, Renewable Energy Sources (RES) are gaining more importance over the globe because of the exhausting nature of the conventional energy sources, rise in earth's temperature due to carbon dioxide emissions, ever increasing oil price, non availability of power supply in the rural areas, etc. [1]-[4]. The energy 
generated from RES depends upon the environmental conditions [5] (i.e. energy generated from solar energy conversion system depends upon the solar irradiation and energy generated from wind energy conversion system depends upon the wind speed), whereas the electrical grid requires constant voltage and frequency. Hence proper power electronic interface must be provided between the renewable energy and the grid for stable operation [5].

In order to connect RES to the grid, two stages of power conversion are used. First stage is to boost up the low voltage output of RES and to track its Maximum Power Point (MPP), whereas the second stage is used to convert DC into AC signal as required by the grid [3]. To increase the efficiency of the grid connected renewable energy systems single stage boost inverters are proposed in the literature [1]-[4]. Single stage power conversion technique reduces the losses, thereby increasing the efficiency, but it suffers from drawbacks like poor Total Harmonic Distortion (THD) at the output voltage which eventually increases the filter size, thereby increasing the cost and size of the total system [6].

To improve the harmonic profile of the output voltage of the inverter Multilevel Inverters (MLIs) are suggested in [1]-[5]. MLIs have nearly sinusoidal output voltage and current waveforms with improved harmonic profile, less stress in power electronic switches due to reduced voltages, lower switching losses when compared to conventional three-level inverters, smaller filter size and reduced electromagnetic interference [6]. In recent years various MLIs are proposed in the literature. Among those commonly used types are diodeclamped MLI [7], capacitor clamped MLI [8], cascaded H-bridge MLI [9]-[11] and modified H-bridge MLI [11] [12]. MLIs are further classified into symmetrical and asymmetrical types. Asymmetrical MLIs (ASMLIs) are capable of producing more levels for the given power electronic devices when compared with symmetrical MLIs (SMLIs) [13]. This paper introduces a modified ASMLI topology suitable for renewable energy sources. The proposed inverter is capable of generating seven levels with two isolated DC sources and six power semiconductor controlled switches. The two isolated DC sources are of different in magnitudes of voltages with the ratio of 1:2. Among the six power semiconductor devices, two devices are bidirectional and four devices are unidirectional devices. The proposed inverter has many advantages like simple in structure, adaptable for integrating RES with the grid, lower THD and lesser number of semiconductor switches.

The remaining part of this paper is structured as follows. The operation and description of the modified ASMLI topology along with switching logic are detailed in Section 2, the suggested ASMLI fed from RES along with proper control system is described in Section 3, Section 4 details the simulation results obtained from MATLAB/SIMULINK and the performance of the system is recapitulated the conclusion.

\section{Circuit Topology}

The proposed topology consists of a two bidirectional switches added to the conventional $\mathrm{H}$ bridge inverter. The proposed topology has been derived from the topology proposed in [10] [13]. The topology proposed in [10] has only one bidirectional switch which is capable of generating only five levels and is of symmetrical type. Whereas the topology proposed in [13] has two bidirectional switches which is capable of generating seven levels, but it has the problem of capacitor voltage balancing when fed to high power loads [2]. Further the MLI proposed in [10] is again of symmetrical in nature. The asymmetrical MLI proposed in this paper requires only two bidirectional switches to generate seven levels further the problem of capacitor voltage balancing does not exist. Figure 1 shows circuit topology of the proposed asymmetrical MLI topology.

The proposed topology of ASMLI consists of two isolated DC sources with the ratio of 1:2, six power semiconductor devices in which two devices are bidirectional (i.e. $A S_{1}$ and $A S_{2}$ ). The switch AS1 is connected between the middle of the leg 1 and to the middle of the two isolated DC sources, where as the switch $\mathrm{AS}_{2}$ is connected between the middle of the leg 2 and to the middle of the DC sources. Figure 2 shows the modes of operation of the proposed inverter. In Figure 2 the conducting paths are shown in dark black lines whereas the non-conducting paths are shown in the light grey colors. Table 1 shows the switching table of the proposed ASMLI, which is capable of generating seven levels. Further the proposed ASMLI is capable of generating higher levels if the basic blocks are connected in cascade.

In order to generate gating signals for the proposed inverter, six level shifted carrier waves are used as shown in Figure 3. The logical diagram for generating the gating signals using the six level shifted carrier waves are shown in Figure 4. From Figure 4 it is very clear that the logic is very simple to implement and uses XOR, NOT and XNOR operations. 


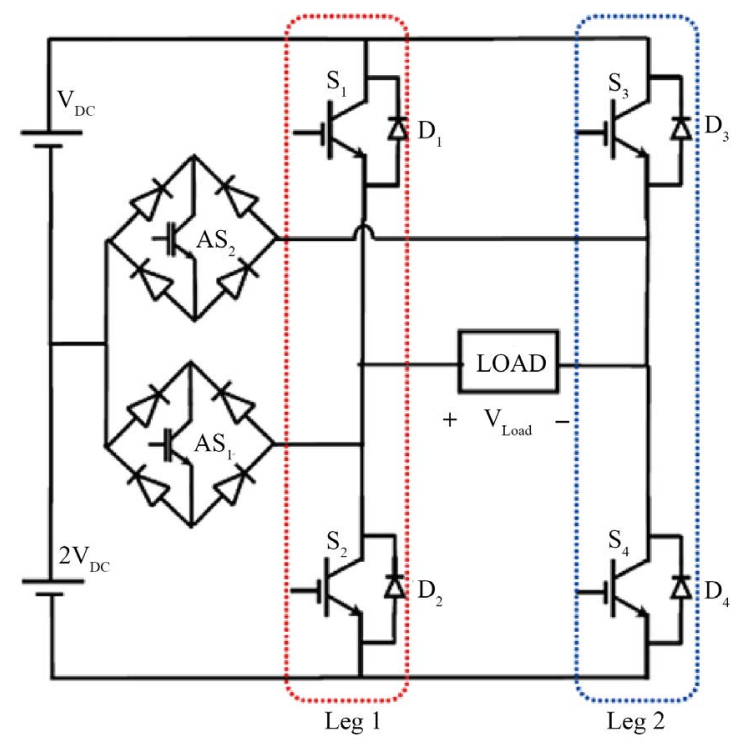

Figure 1. Proposed asymmetrical MLI topology.

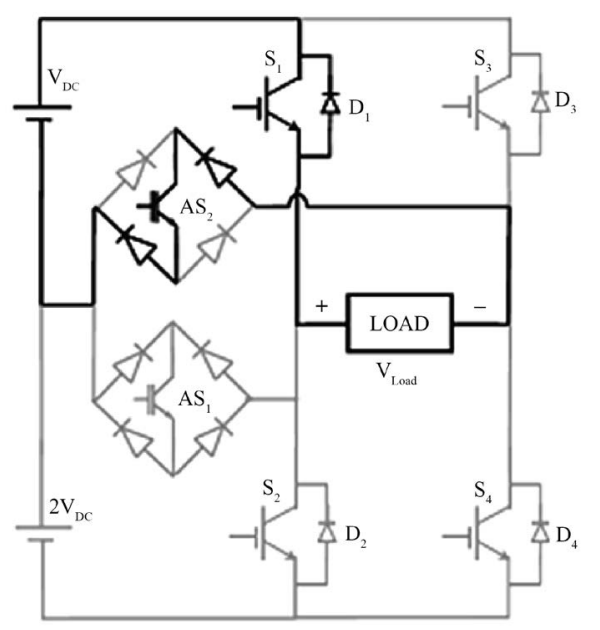

(a)

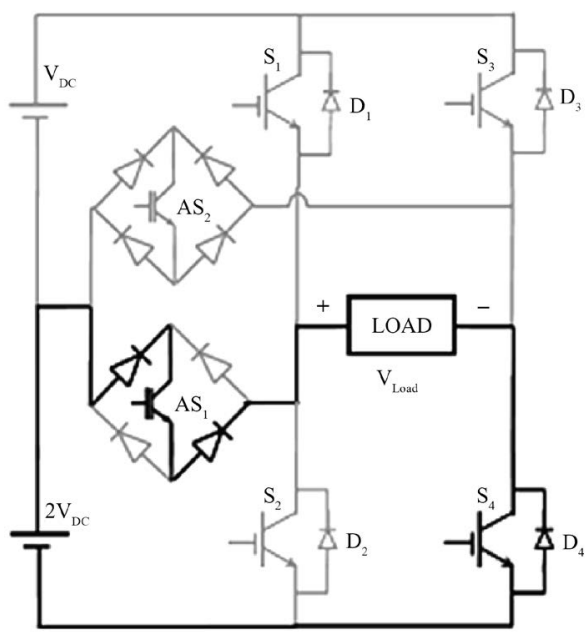

(c)

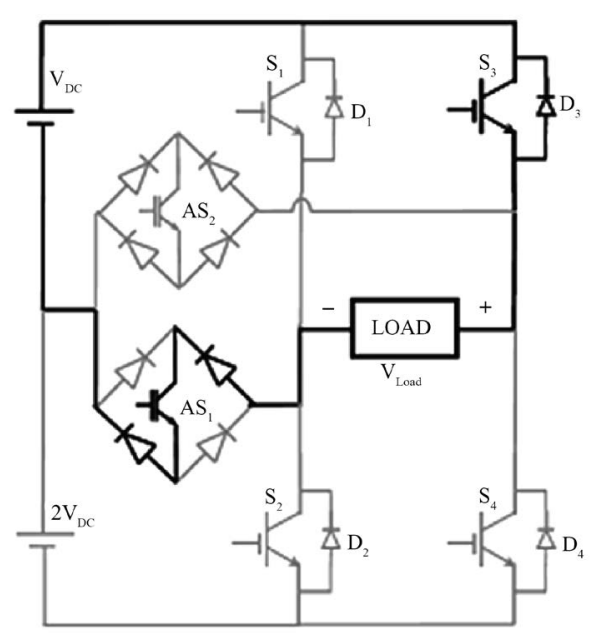

(b)

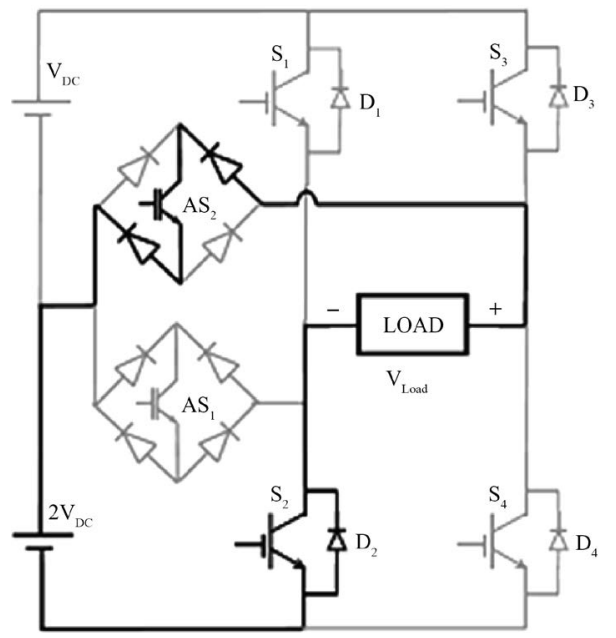

(d) 


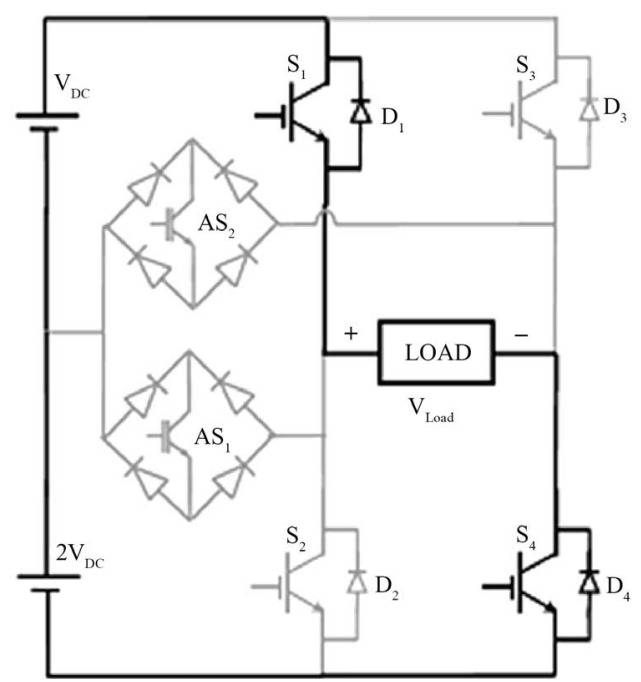

(e)

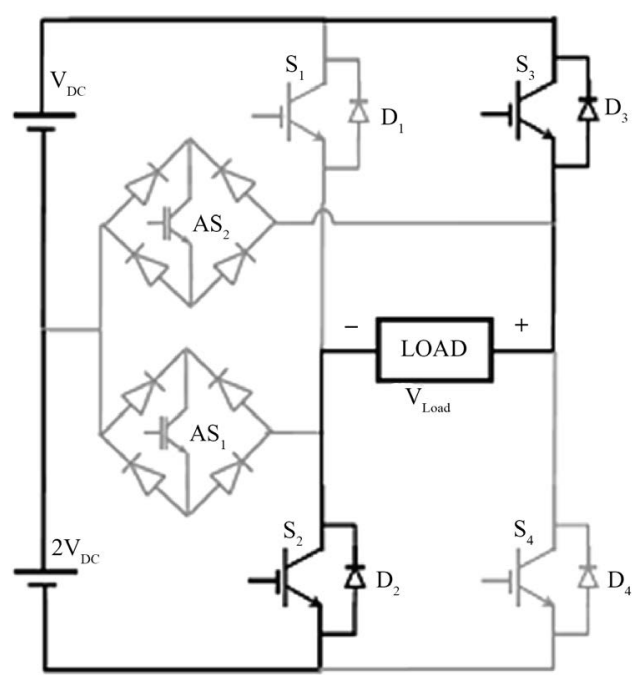

(f)

Figure 2. (a) $V_{L O A D}=+V_{D C} ;$ (b) $V_{L O A D}=-V_{D C} ;$ (c) $V_{L O A D}=+2 V_{D C} ;$ (d) $V_{L O A D}=-2 V_{D C} ; \quad$ (e) $V_{L O A D}=+3 V_{D C} ; \quad$ (f)
$V_{L O A D}=-3 V_{D C}$.

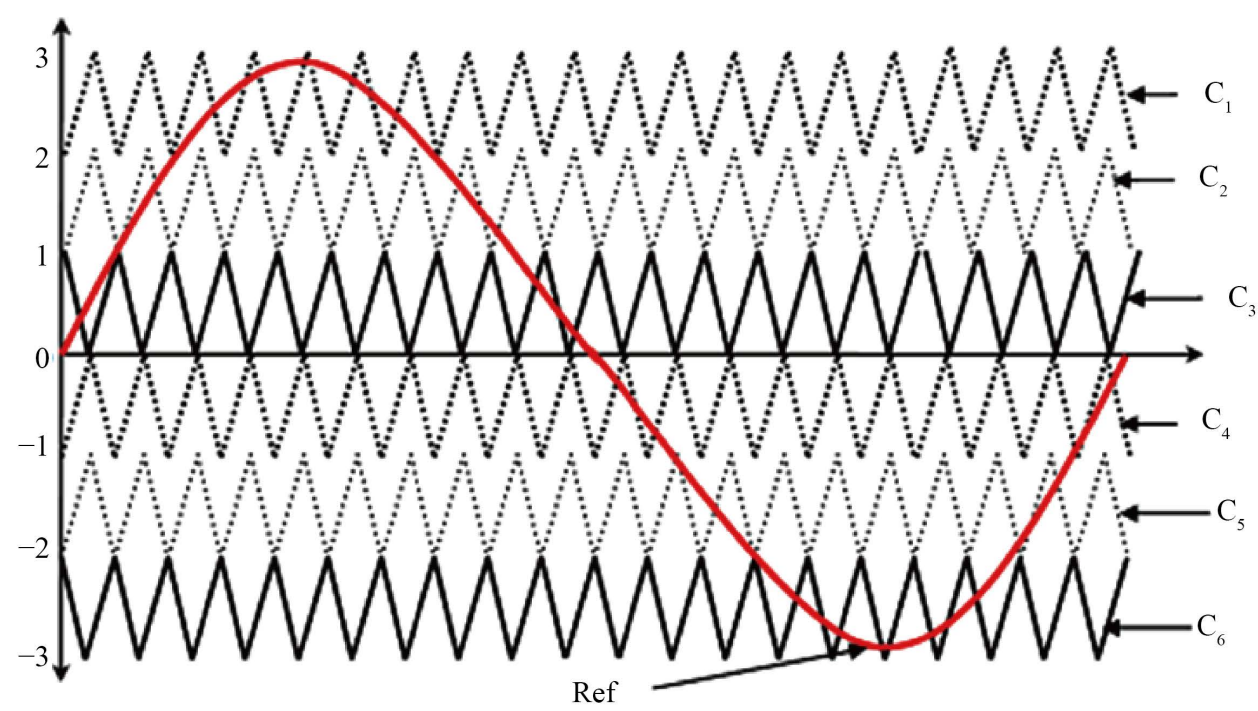

Figure 3. Carrier signals used for generating gating signals.

Table 1. Switching logic of the basic block of the proposed ASMLI.

\begin{tabular}{cccccccc}
\hline$S_{1}$ & $S_{2}$ & $S_{3}$ & $S_{4}$ & $A S_{1}$ & $A S_{2}$ & $V_{\text {LOAD }}$ & Reference \\
\hline ON & OFF & OFF & ON & OFF & OFF & $+3 V_{D C}$ & Figure 2(e) \\
OFF & OFF & OFF & ON & ON & OFF & $+2 V_{D C}$ & Figure 2(c) \\
ON & OFF & OFF & OFF & OFF & ON & $+V_{D C}$ & Figure 2(a) \\
OFF & OFF & OFF & OFF & ON & ON & 0 & - \\
OFF & OFF & ON & OFF & ON & OFF & $-V_{D C}$ & Figure 2(b) \\
OFF & ON & OFF & OFF & OFF & ON & $-2 V_{D C}$ & Figure 2(d) \\
OFF & ON & ON & OFF & OFF & OFF & $-3 V_{D C}$ & Figure 2(f) \\
\hline
\end{tabular}




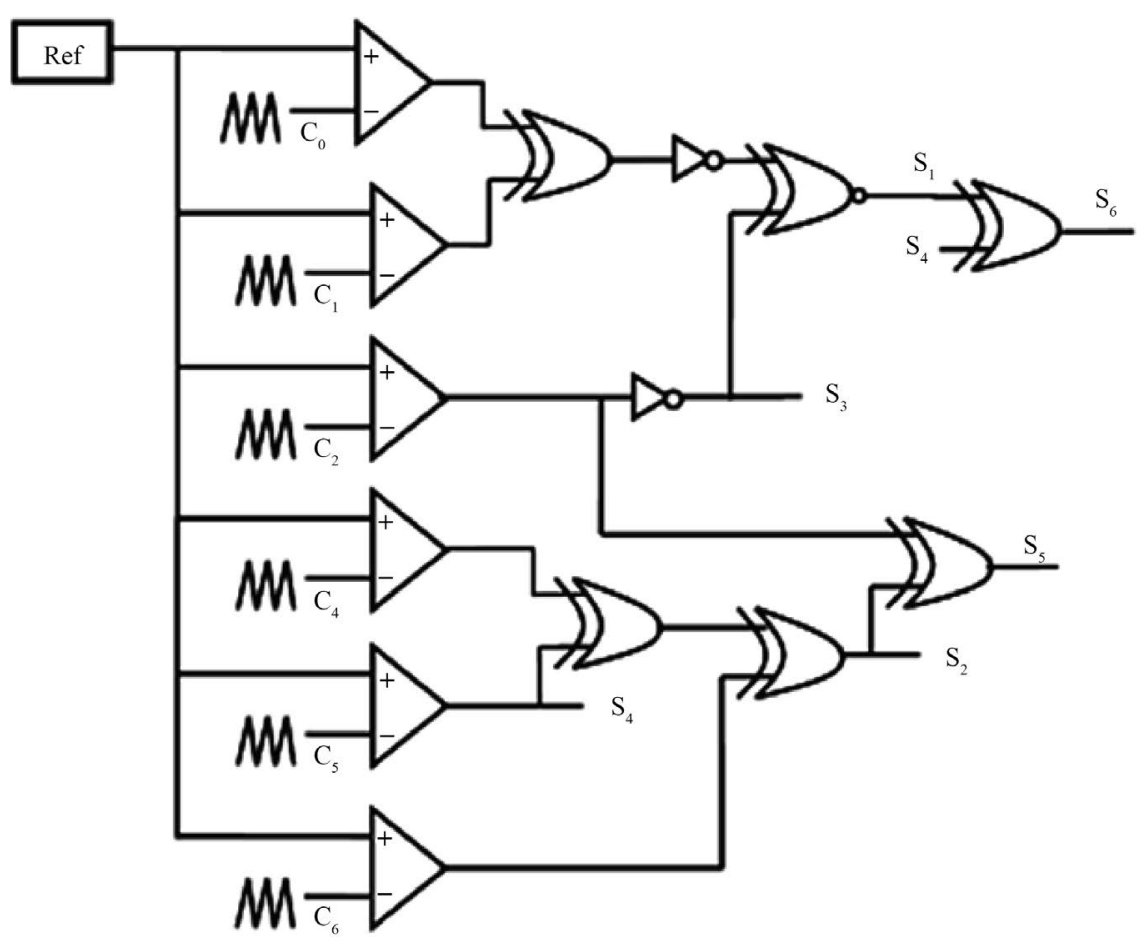

Figure 4. Logic diagram for generating gating signals for the proposed inverter.

\section{Proposed Inverter Fed from Renewable Energy Sources}

The proposed inverter is a best fit for grid connected renewable energy applications. Figure 5 shows the proposed inverter fed from solar photovoltaic and wind turbine driven PMDC generator. The upper DC source is fed from Solar PV, where as the lower DC source is fed from WT driven PMDC generator. The operating point of solar PV module is decided by solar radiation, temperature of PV module and the resistance of the load. For a given cell temperature and solar radiation, there is an exclusive operating point of the PV array in its PV curve with maximum output power. Hence Maximum Power Point Tracking (MPPT) is essential in PV arrays in order to draw maximum power from it irrespective of the climatic and load conditions [14]. A similar situation exists in Wind Turbine also [5]. Generally DC-DC boost converter is used next to PV module for two main reasons. Primary reason is to track the MPP and the secondary reason is to boost up the low output voltage of PV module to a higher level. Hence the DC-DC boost converters duty cycle is dependent on the MPPT algorithm. Thus when the environmental conditions vary MPPT algorithm will change the duty cycle which in turn reduces or increases the output voltage of the boost converter. But the DC input voltage of the inverter should have a stiff value when it is connected to the grid. Hence two DC-DC boost converters are used in cascade, one is to track the MPP and the other is to maintain the DC-link voltage (i.e. input voltage of the inverter) to a stiff value. Similar option is used in the WT also.

\subsection{Maximum Power Point Tracking}

The PV and VI Characteristics of TATA BP $180 \mathrm{~W}$ panel is shown in Figure 6 for various irradiations and cell temperature. It is very clear from Figure 6 that the location of the maximum power point varies when the environmental condition varies (i.e. irradiation and module temperature). Similarly the wind power vs. turbine speed characteristics for various wind velocities is shown in Figure 7. It can be observed from Figure 7 if wind velocity varies MPP also varies. Hence MPPT is essential in the case of PV arrays and WT. The details of PV module and WT coupled PMDC machine is given in Table 2. There is lot of MPPT algorithms proposed in the literature [13]-[16]. Among the various MPPT algorithms perturb and observe and Incremental conductance algorithms are most popular due to their simplicity and easy implementation [15]. But these algorithms have draw back in selecting the incremental value of the control factor. When the incremental value is chosen very 


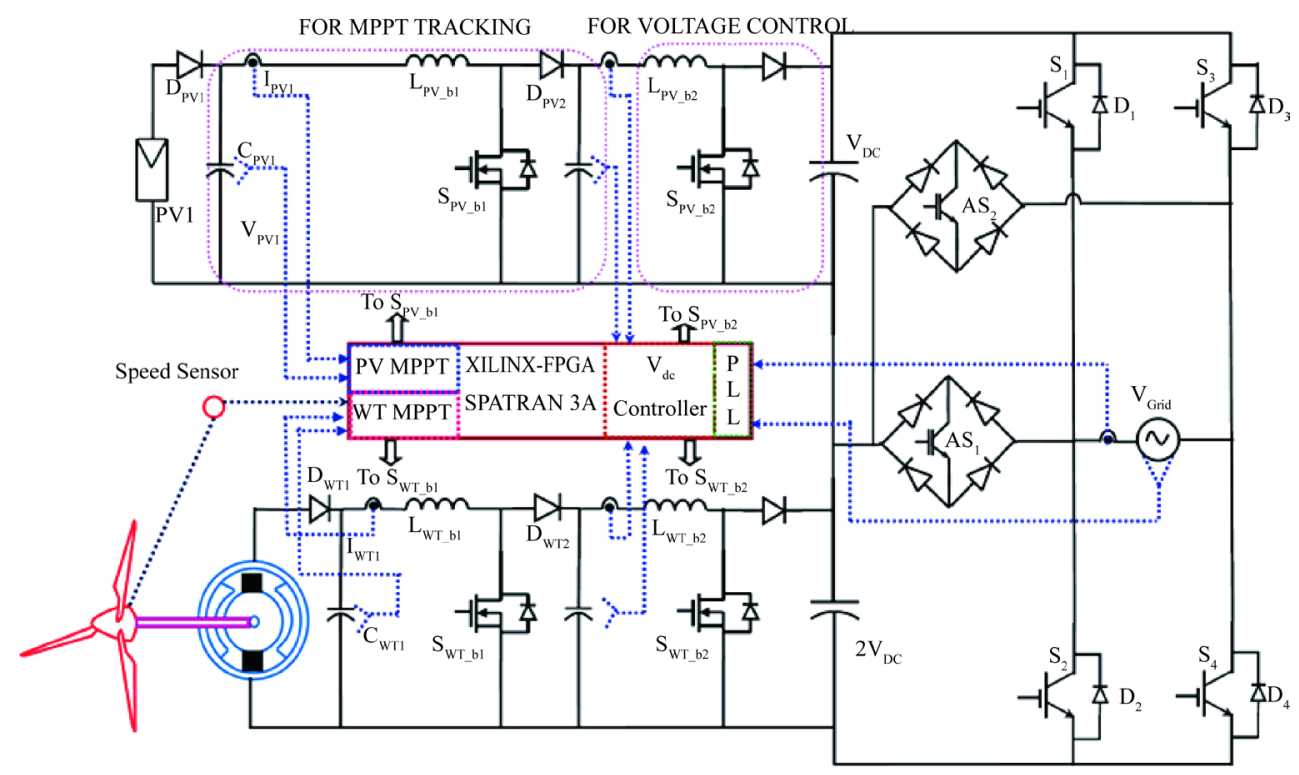

Figure 5. System configuration of the proposed inverter fed from PV arrays and WT driven PMDC generator.

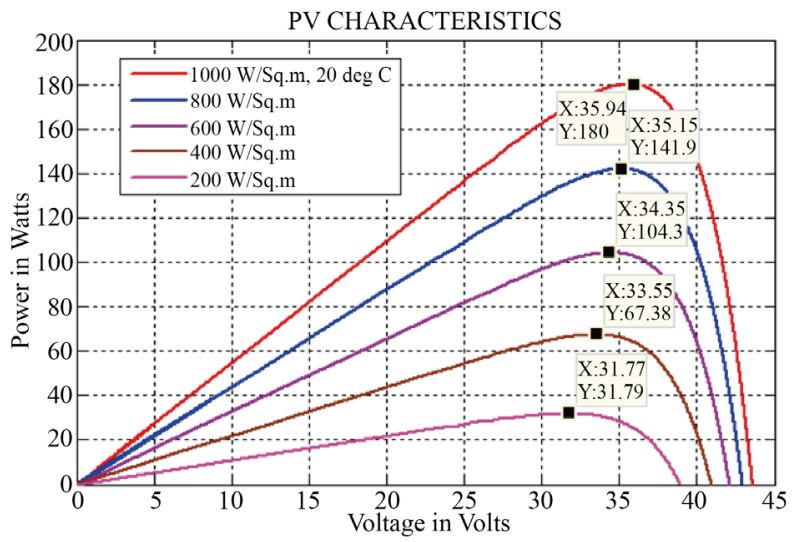

(a)

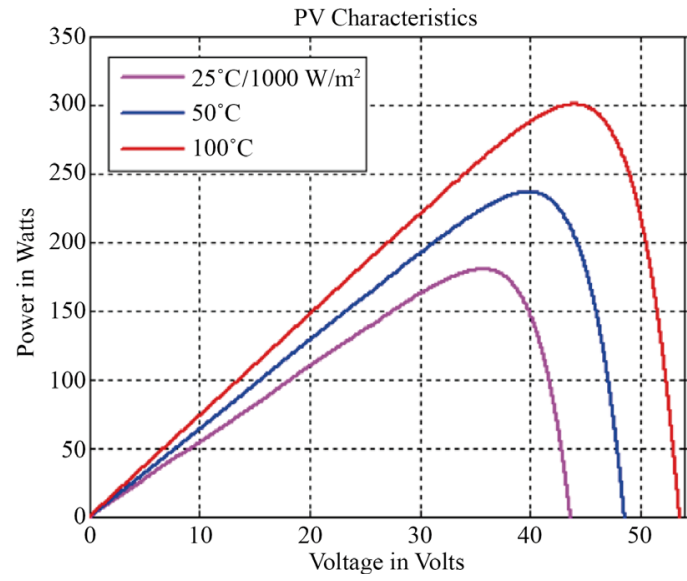

(c)

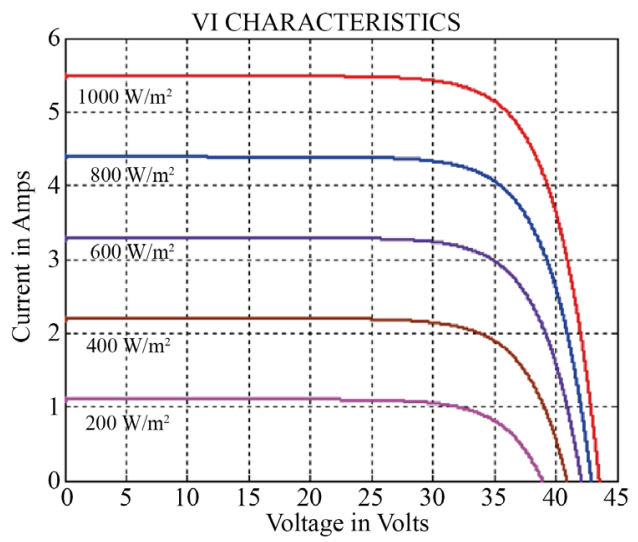

(b)

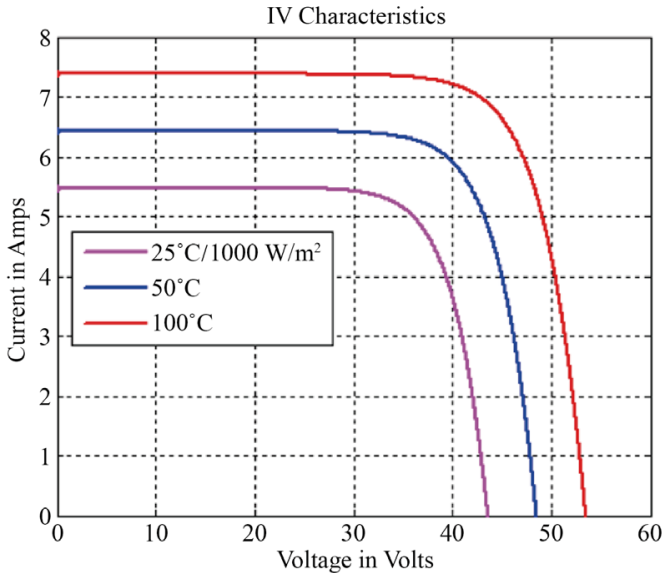

(d)

Figure 6. (a) PV characteristics of PV array for constant temperature $\left(25^{\circ} \mathrm{C}\right)$; (b) IV characteristics of PV array for constant temperature $\left(25^{\circ} \mathrm{C}\right)$; (c) PV characteristics of PV array for constant irradiance $\left(1000 \mathrm{~W} / \mathrm{m}^{2}\right)$; (d) IV characteristics of PV array for constant irradiance $\left(1000 \mathrm{~W} / \mathrm{m}^{2}\right)$. 


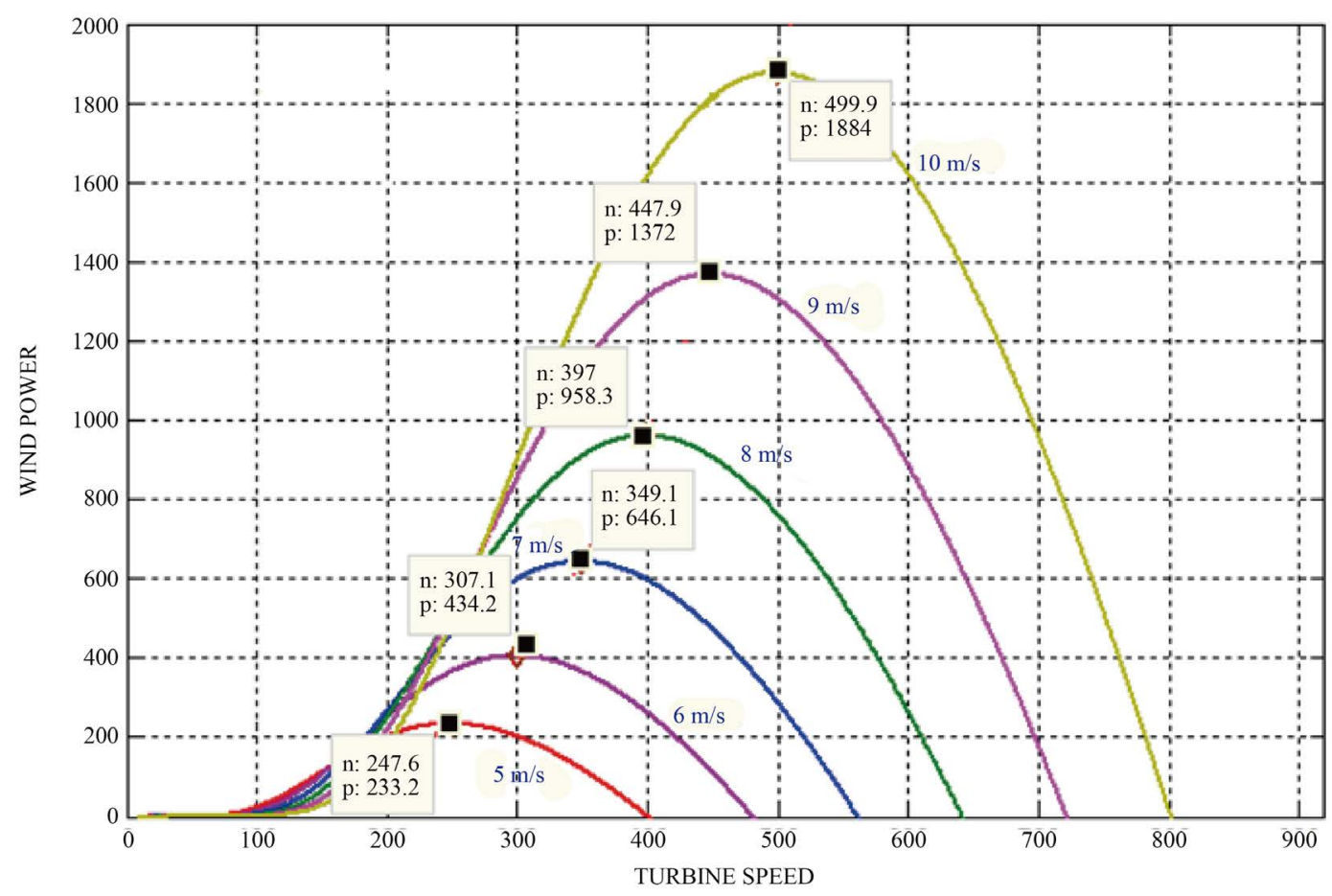

Figure 7. Turbine speed vs. turbine power for various wind velocities.

Table 2. PV module, WT and PMDC parameters.

\begin{tabular}{cccccc}
\hline PV Module & \multicolumn{3}{c}{ Wind Turbine } & \multicolumn{2}{c}{ PMDC } \\
\hline Power Output $P_{M A X}$ & $180 \mathrm{~W}$ & Rated Power & $1.8 \mathrm{~kW}$ & Rated Power & $1.1 \mathrm{~kW}$ \\
Voltage at $P_{M A X} V_{M P P}$ & $35.8 \mathrm{~V}$ & Rated Wind Speed & $10 \mathrm{~m} / \mathrm{s}$ & Armature Voltage & $37.2 \mathrm{~V}$ \\
Current at $P_{M A X} V_{M P P}$ & $5.03 \mathrm{~A}$ & Radius & $1.525 \mathrm{~m}$ & Rated RPM & 1000 \\
Open Circuit Voltage & $43.6 \mathrm{~V}$ & Gear Ratio & 5 & Armature Resistance & 0.3 \\
Short Circuit Current & $5.48 \mathrm{~A}$ & Air density & $1.08 \mathrm{~m}^{3} / \mathrm{kg}$ & Armature Inductance & $0.06 \mathrm{mH}$ \\
\hline
\end{tabular}

small, it gives poor dynamic performance and the algorithm becomes very slow. On the other hand when large value of chosen, the steady state error becomes very high [15]. Hence this paper proposes sliding mode based MPPT tracking for fast tracking with good dynamic and steady state performance.

In sliding mode control sliding surface is determined by finding the MPP for various environmental conditions (i.e. irradiation, module temperature and wind velocity) through simulation. Once the MPP is determined for various environmental conditions, sliding surface equation is determined by using curve fitting toolbox in MATLAB/SIMULINK. The sliding surface equation for PV module and WT are shown in Figure 8. When the result of sliding surface equation is greater than zero the boost converter switch is turned ON, on the other hand when it is less than zero it is turned OFF.

The sliding surface of PV module is given by

$$
Y=0.02499 X^{3}-2.346 X^{2}+73.82 X-778.1
$$

where $Y$ is the PV module current and $X$ is the PV module Voltage. Since the sliding surface equation is passing through the maximum power points, the result of the above equation should be zero to ensure MPP. Hence PV module current and voltage are sensed and Equation (1) is calculated instantaneously. When the result of the above equation is greater than zero, the switch $S_{\text {pvb1 }}$ (shown in Figure 5) is turned ON, else it is turned OFF. In order to evaluate the proposed sliding mode algorithm, step change in the irradiance is given and the corres- 


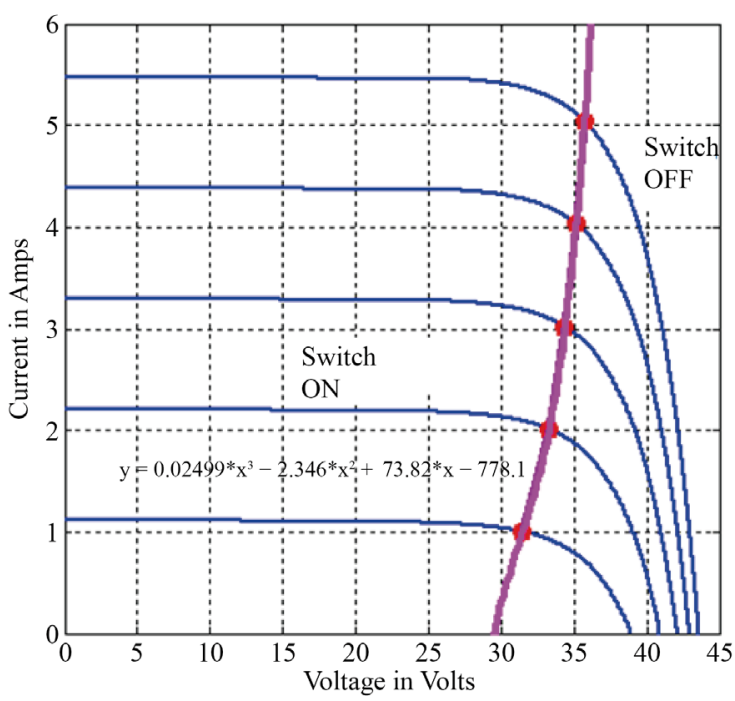

(a)

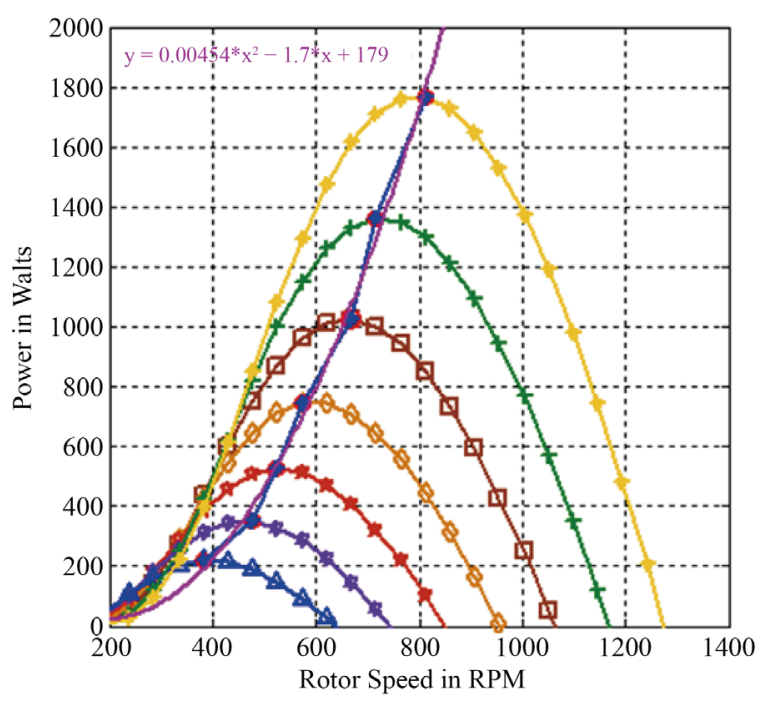

(b)

Figure 8. (a) Sliding surface of PV module (b) Sliding surface of WT.

ponding power output is measured and compared with actual MPP power as shown in Figure 9. It is evident from Figure 9 that the panel is generating 180 Watts when irradiance is $1000 \mathrm{~W} / \mathrm{m}^{2}$.

Similarly the sliding surface of WT is given by

$$
Y=0.00454 X^{2}-1.7 X+179
$$

where $Y$ is the power output of PMDC generator and $X$ is the WT rotor speed. When the result of the above equation is greater than zero, the switch $S_{W T b 1}$ (shown in Figure 5) is turned ON, else it is turned OFF. In order to evaluate the proposed sliding mode algorithm, step change in the wind speed is given and the corresponding power output is measured and compared with actual MPP power as shown in Figure 10.

By comparing Figure 9 with data points of Figure 6(a), it is very clear that steady state error is very minimum and also it has good dynamic response. Similar comparison can be made between Figure 10 and Figure 7 to evaluate the performance of sliding mode control of WT.

\subsection{Cascaded Boost Converters}

Two boost converters are connected in cascade between the RES and the inverter DC sources as shown in Figure 5. The output of the MPPT boost converter of PV module is shown in Figure 11. Since the primary task of the MPPT boost converter is track the MPP, the output voltage of the MPPT boost converter also varies when there is a change in environmental conditions as shown in Figure 11. But the DC link voltage of the inverter should be maintained constant for stable grid integration. Hence another Boost converter is connected in cascade with MPPT boost converter. The main purpose of the second boost converter is to maintain constant voltage in the DC link. Figure 12 shows the output voltage obtained from the second boost converter, which remains constant at 130 volt.

Similarly the output voltage of MPPT boost converter of WT also varies when there is a variation in the wind speed. Hence the Voltage control boost converter is connected in cascaded to have stiff voltage at the DC link of the inverter. Figure 13 shows the output voltage of voltage control boost converter of WT. It is evident from Figure 13 that the output voltage of WT voltage control boost converter is 260 volts.

\section{Grid Integration}

The proposed inverter fed from renewable energy sources is connected to grid through control components as shown in Figure 5. The control block diagram of the grid integration is shown in Figure 14.

The upper DC link of the proposed inverter (Figure 5) is set to 130 volts where as the lower DC link voltage is set to 260 volts. The output voltage of the proposed inverter with seven levels is shown in Figure 15(a) for 


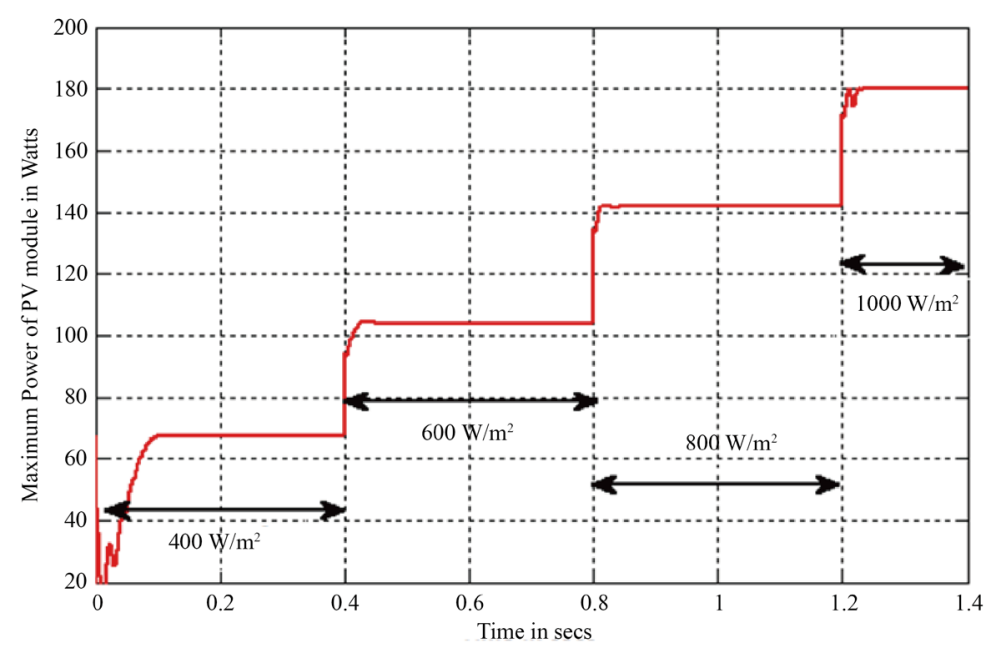

Figure 9. MPPT of PV module using sliding mode algorithm.

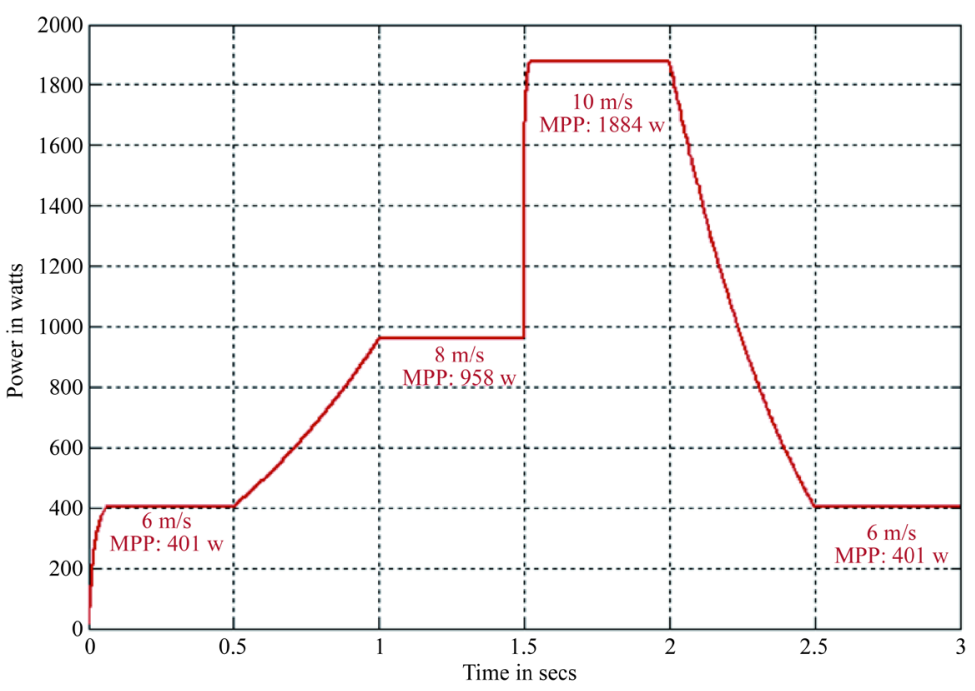

Figure 10. MPPT of wind turbine using sliding mode algorithm.

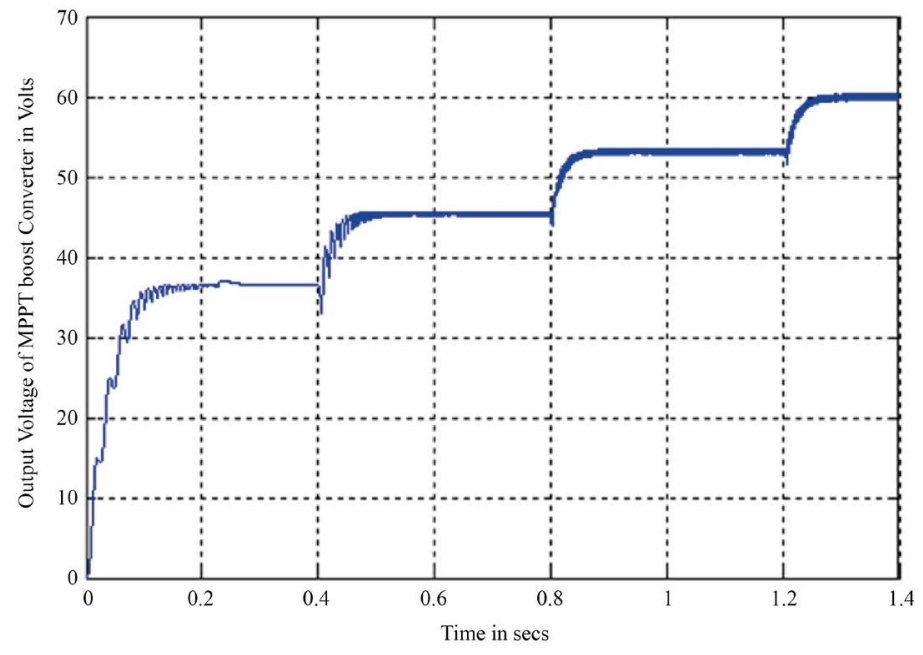

Figure 11. Output voltage of MPPT boost converter of PV module. 


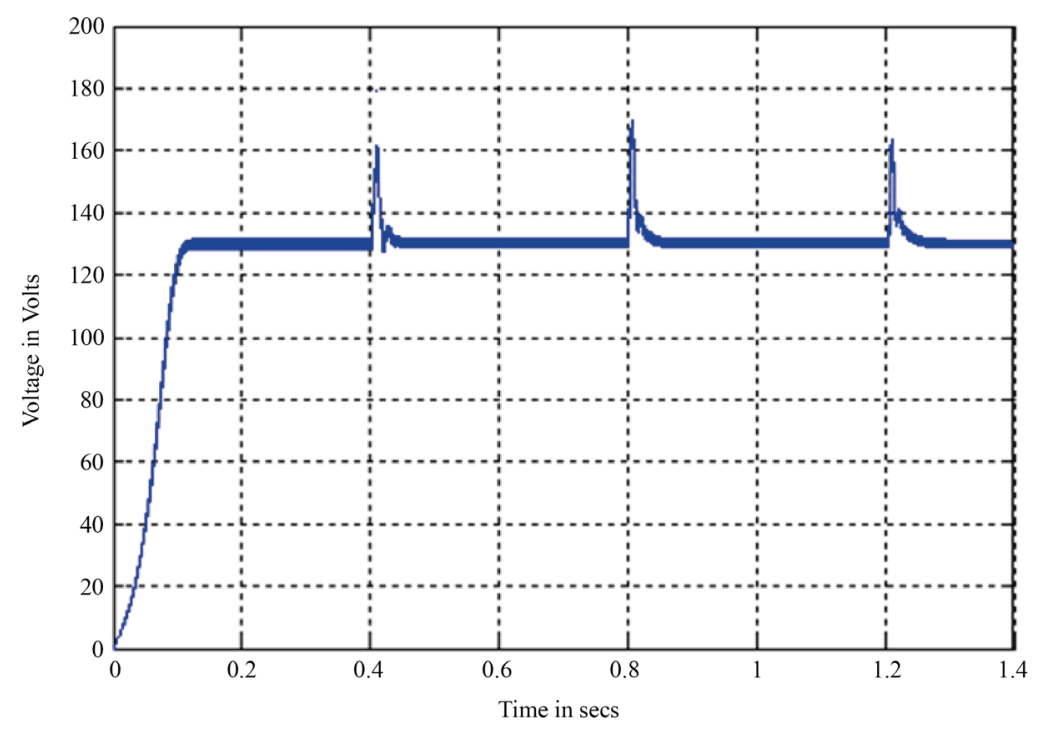

Figure 12. Output voltage of voltage control boost converter of PV module.

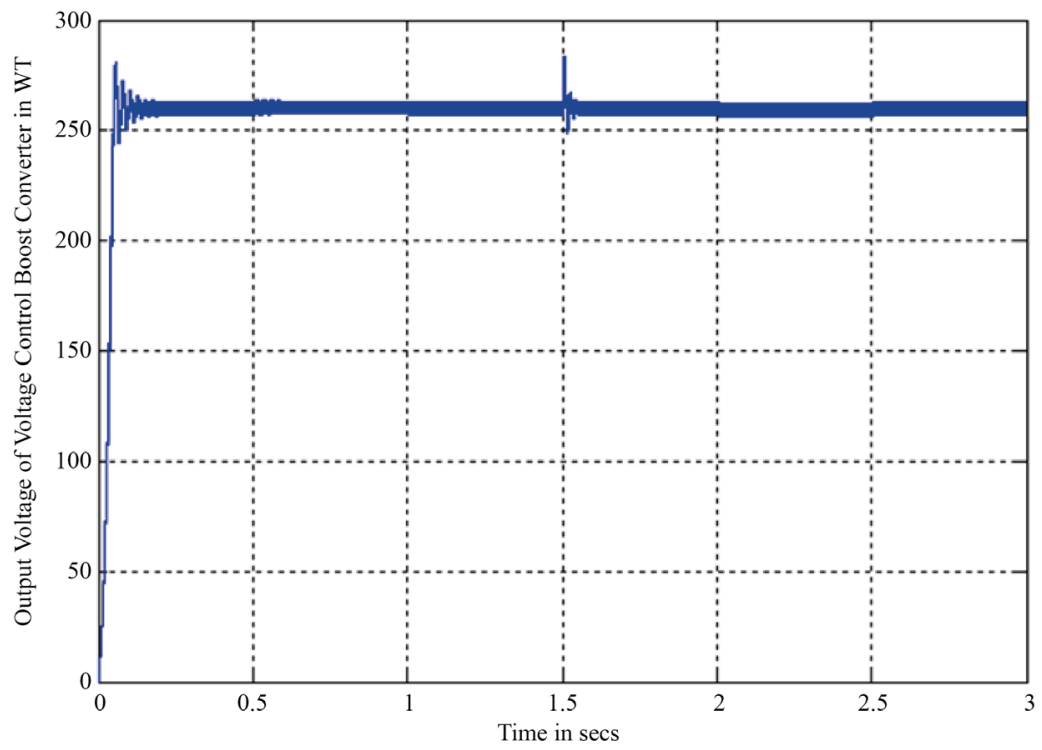

Figure 13. Output voltage of voltage control boost converter of WT.

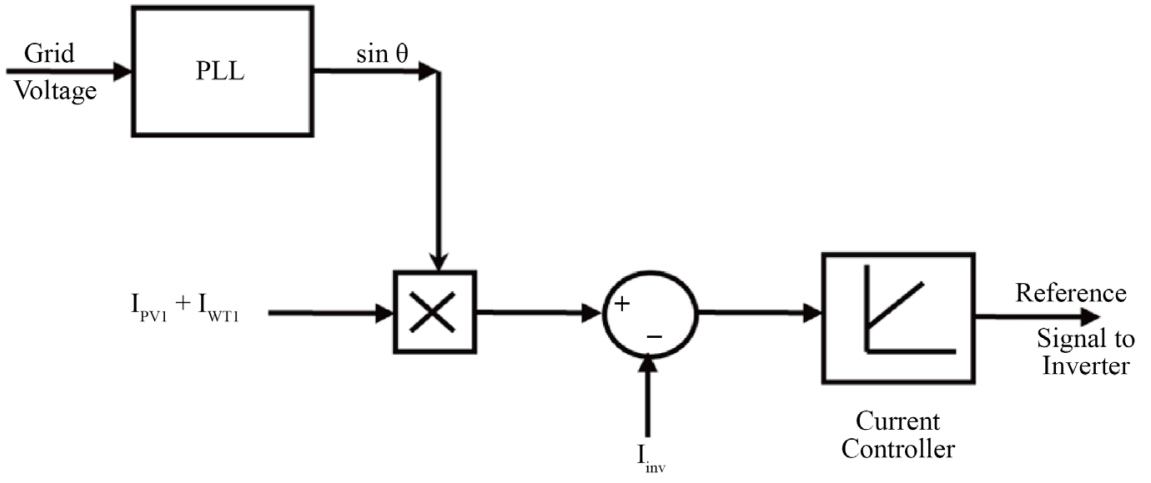

Figure 14. Control block diagram of grid integration. 


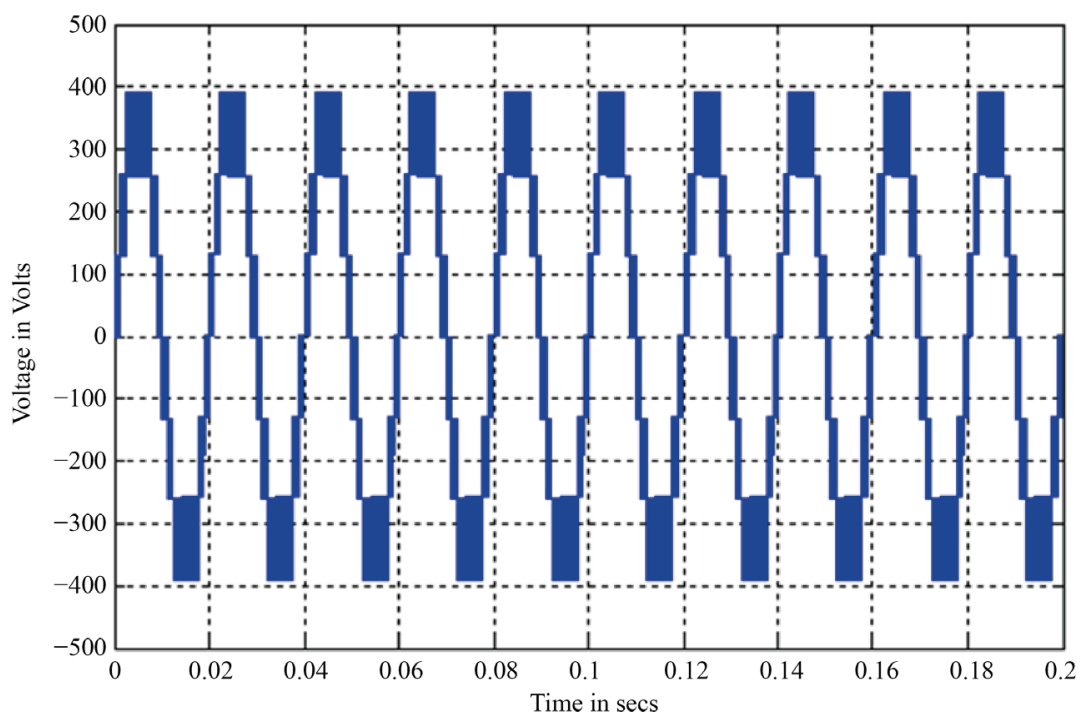

(a)

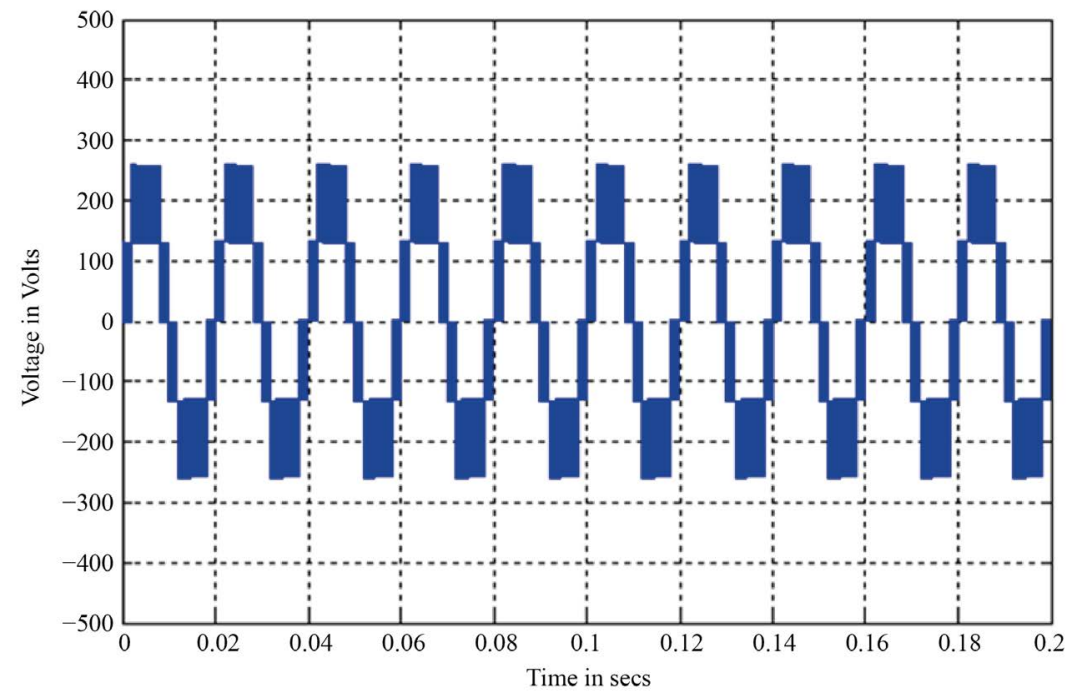

(b)

Figure 15. (a) Output voltage of proposed inverter when the modulation index is 0.95 (seven levels); (b) Output voltage of proposed inverter when the modulation index is 0.6 (five levels).

modulation index of 0.95 . When the modulation index is reduced to 0.6 , the inverter is capable of generating only five levels which is shown in Figure 15(b). Figure 16 shows the capability of the proposed inverter when there is sud-den change in the grid voltage (i.e. Grid Disturbance). It can be seen in Figure 16 that when the grid voltage falls the inverter modulation index is adjusted itself so that the inverter voltage also reduces.

Figure 17 shows the grid voltage and grid current waveform during the time of grid disturbance. It is very clear from Figure 17 that the grid voltage and grid current are in phase and the power factor is almost unity. It can be seen from Figure 18 that the reference current from MPPT controllers and the inverter current are one over the other and tracks very perfectly.

\section{Conclusion}

In this paper a novel asymmetrical multilevel inverter is proposed. The operation of the proposed inverter is discussed and simulated in MATLAB/SIMULINK environment and the results are presented. The proposed inverter is fed from renewable energy sources through two boost converters connected in cascade: one for 


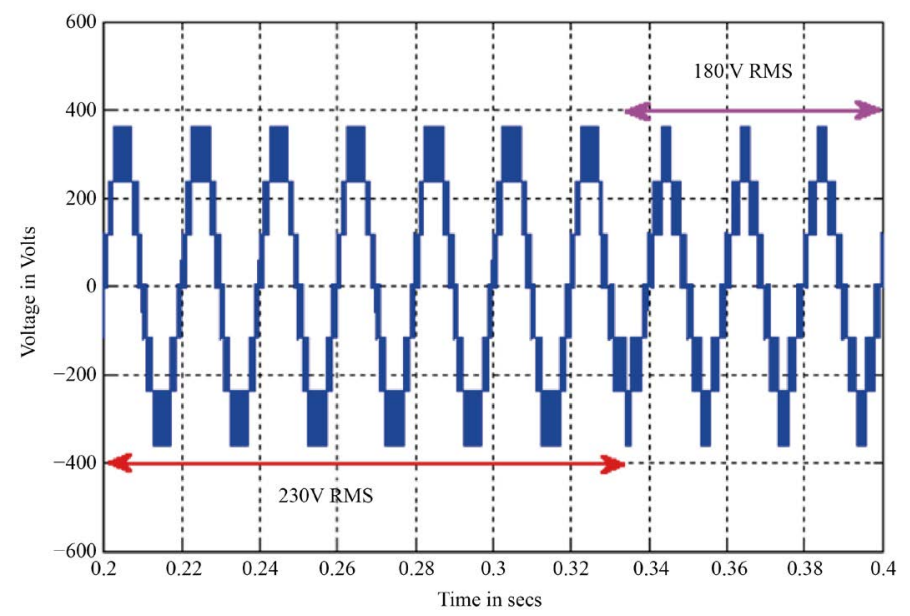

(a)

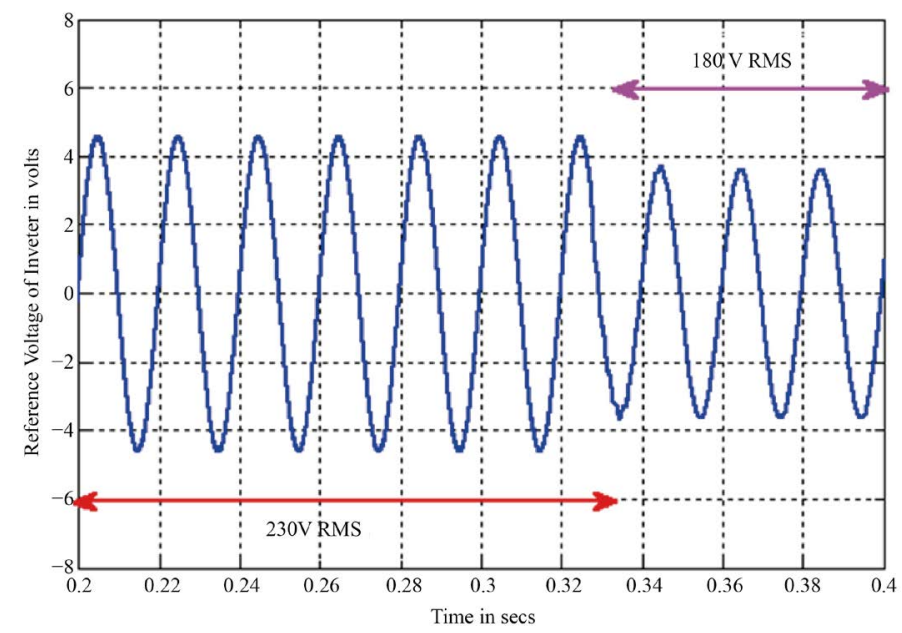

(b)

Figure 16. (a) Output Voltage of the proposed inverter due to grid disturbance; (b) Reference waveform of the inverter due to grid disturbance.

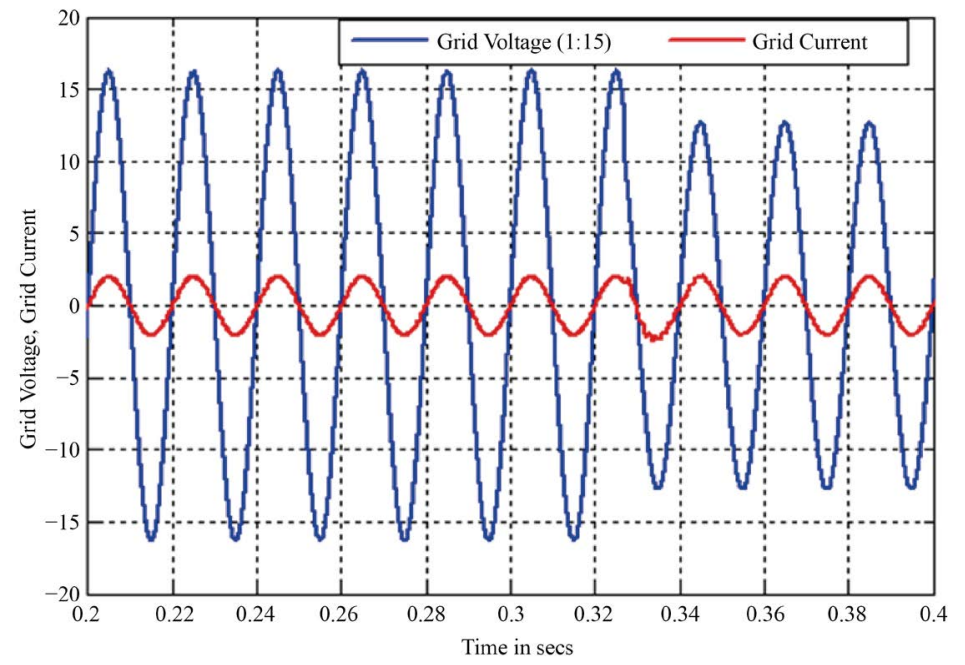

Figure 17. Grid voltage and grid current. 


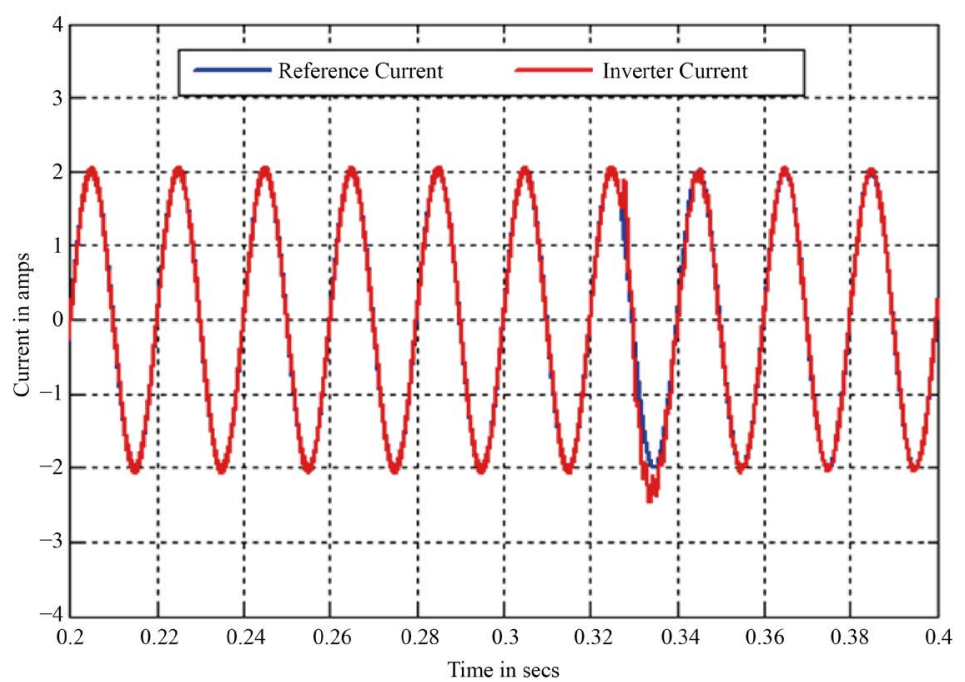

Figure 18. Reference and inverter current.

tracking the MPP and another for voltage control. Further the proposed inverter is connected to the single phase grid through proper control structure. The complete system is simulated and the results are presented.

\section{References}

[1] Carrasco, J.M., Franquelo, L.G., Bialasiewicz, J.T., Galvan, E., Guisado, R.P., Prats, M.A. and Moreno-Alfonso, N. (2006) Power-Electronic Systems for the Grid Integration of Renewable Energy Sources: A Survey. IEEE Transactions on Industrial Electronics, 53, 1002-1016. http://dx.doi.org/10.1109/TIE.2006.878356

[2] Nami, A., Zare, F., Ghosh, A. and Blaabjerg, F. (2011) A Hybrid Cascade Converter Topology with Series-Connected Symmetrical and Asymmetrical Diode-Clamped H-Bridge Cells. IEEE Transactions on Power Electronics, 26, 51-65. http://dx.doi.org/10.1109/TPEL.2009.2031115

[3] Tolbert, L.M. and Peng, F.Z. (2000) Multilevel Converters as a Utility Interface for Renewable Energy Systems. IEEE Power Engineering Society Summer Meeting, Vol. 2, 1271-1274. http://dx.doi.org/10.1109/pess.2000.867569

[4] Calais, M., Agelidis, V.G. and Meinhardt, M. (1999) Multilevel Converters for Single-Phase Grid Connected Photovoltaic Systems: An Overview. Solar Energy, 66, 325-335. http://dx.doi.org/10.1016/S0038-092X(99)00035-3

[5] Raj, I.G.C., Kaliamoorthy, M., Rajasekaran, V. and Sekar, R.M. (2015.) Single-Phase Cascaded Grid Connected Multilevel Inverter for Interfacing Renewable Energy Sources with Microgrid. Journal of Solar Energy Engineering, 137, 051004. http://dx.doi.org/10.1115/1.4030886

[6] Kaliamoorthy, M., Rajasekaran, V. and Raj, I.G.C. (2014) Single-Phase Fifteen-Level Grid-Connected Inverter for Photovoltaic System with Evolutionary Programming Based MPPT Algorithm. Solar Energy, 105, 314-329. http://dx.doi.org/10.1016/j.solener.2014.03.031

[7] Merahi, F., Berkouk, E.M. and Mekhilef, S. (2014) New Management Structure of Active and Reactive Power of a Large Wind Farm Based on Multilevel Converter. Renewable Energy, 68, 814-828. http://dx.doi.org/10.1016/j.renene.2014.03.007

[8] Merahi, F. and Berkouk, E.M. (2013) Back-to-Back Five-Level Converters for Wind Energy Conversion System with DC-Bus Imbalance Minimization. Renewable Energy, 60, 137-149. http://dx.doi.org/10.1016/j.renene.2013.05.001

[9] Sastry, J., Bakas, P., Kim, H., Wang, L. and Marinopoulos, A. (2014) Evaluation of Cascaded H-Bridge Inverter for Utility-Scale Photovoltaic Systems. Renewable Energy, 69, 208-218. http://dx.doi.org/10.1016/j.renene.2014.03.049

[10] Rahim, N.A., Selvaraj, J. and Krismadinata, C. (2010) Five-Level Inverter with Dual Reference Modulation Technique for Grid-Connected PV System. Renewable Energy, 35, 712-720. http://dx.doi.org/10.1016/j.renene.2009.08.021

[11] Calais, M., Agelidis, V.G. and Dymond, M.S. (2001) A Cascaded Inverter for Transformer Less Single-Phase GridConnected Photovoltaic Systems. Renewable Energy, 22, 255-262. http://dx.doi.org/10.1016/S0960-1481(00)00069-0

[12] Testa, A., De Caro, S., La Torre, R. and Scimone, T. (2012) A Probabilistic Approach to Size Step-Up Transformers for Grid Connected PV Plants. Renewable Energy, 48, 42-51. http://dx.doi.org/10.1016/j.renene.2012.04.012

[13] Kaliamoorthy, M., Rajasekaran, V., Raj, I.G.C. and Raj, L.H.T. (2014) Experimental Validation of a Cascaded Single 
Phase H-Bridge Inverter with a Simplified Switching Algorithm. Journal of Power Electronics, 14, 507-518. http://dx.doi.org/10.6113/JPE.2014.14.3.507

[14] Tian, Y., Xia, B.Z., Xu, Z.H. and Sun, W. (2014) Modified Asymmetrical Variable Step Size Incremental Conductance Maximum Power Point Tracking Method for Photovoltaic Systems. Journal of Power Electronics, 14, 156-164. http://dx.doi.org/10.6113/JPE.2014.14.1.156

[15] Kaliamoorthy, M., Sekar, R.M. and Raj, I.G.C. (2010) Solar Powered Single Stage Boost Inverter with ANN based MPPT algorithm. IEEE International Conference on Communication Control and Computing Technologies, Ramanathapuram, 7-9 October 2010, 165-170. http://dx.doi.org/10.1109/iccct.2010.5670545

[16] Kaliamoorthy, M., Rajasekaran, V., Raj, I.G.C. and Raj, L.H.T. (2014) Generalized hybrid switching topology for single phase modular multilevel inverter. IET Power Electronics, 7, 2472-2485.

http://dx.doi.org/10.1049/iet-pel.2013.0847 